\title{
La historia como traición en la novela chilena de los últimos 50 años ${ }^{1}$
}

\section{History and betrayal in chilean novel of the last 50 years}

\author{
Antonio Ostornol Almarza ${ }^{2}$ \\ Universidad Finis Terrae (Chile)
}

Recibido: 17-06-15

Aprobado: 19-07-15

\section{Resumen}

El presente artículo recorre la forma en que la figura de la traición se instala en la narrativa chilena de las últimas décadas, como un modo de representación de la historia reciente del país. A partir del último discurso de Salvador Allende, donde se representa el golpe de estado de 1973 como un gran acto de traición, se analiza un conjunto de novelas de escritores pertenecientes a tres de las últimas generaciones literarias del país. La historia, entendida como un discurso que se le ofrece a cada ciudadano, se percibe como traidora, en la medida que decepciona el sentido de identidad nacional, las utopías históricas o la memoria.

Palabras-clave: Chile, historia, novela contemporánea, representación, traición.

\footnotetext{
${ }^{1}$ Este artículo es parte de la investigación "Historia reciente de Chile y narrativa contemporánea: simetrías y refracciones" que se realiza con fondos de la Universidad Finis Terrae, y ha contado con la inestimable colaboración del licenciado en literatura y ciencias del lenguaje, Ignacio Cobo.

22(aostornol@uft.cl). Formación académica: D.E.A Diplome des Etudes d'Aprofondissation (Master 2), Institut des Hautes Etudes de l'Amérique Latine, Sorbonne III, París, Francia, 1985. Profesor de estado en castellano, Pontificia Universidad Católica de Chile, 1981. Publicaciones recientes: Dubrovnik, Santiago, Editorial Cuarto Propio, 2011. Premio Municipal de novela, Ilustre Municipalidad de Santiago, 2012. Premio José Nuez-Martín, otorgado por la Fundación José NuezMartín y la Facultad de letras de la Pontificia Universidad Católica de Chile, a la mejor novela chilena 2012-2013
} 


\begin{abstract}
This is a walk through the settlement of the concept of betrayal in Chilean novel during the last decades, as a way to depict the country's recent history. Starting with Salvador Allende's last speech referring to the 1973 coup d'état as an act of treason, the analysis covers a series of novels authored by members of the last three generations of Chilean novelists. Taken as a speech delivered to individual citizens, history is perceived as deceptive in that it betrays their sense of national identity, historical utopias or remembrance.
\end{abstract}

Key-words: Chile, history, contemporary novel, portrayal, betrayal.

Hablar de la narrativa chilena de los últimos 50 años y la representación de la historia política en ella, implica necesariamente referirnos a la literatura que se escribió en Chile (en el exilio o al interior del país), a partir del golpe de estado de 1973. Este acontecimiento marcó, prácticamente en todas las esferas de los fenómenos sociales, un antes y un después. Se interrumpió un cierto devenir histórico que parecía generar un sentimiento fuerte de identidad nacional y adhesión a una forma de vida colectiva estable, propia de una democracia. La instalación del régimen militar en Chile terminó con este modo de convivencia e instauró nuevos patrones culturales, sociales, políticos y económicos que resultaron traumáticos para el país.

La literatura no quedó al margen de este proceso. A comienzos de los 60 , la narrativa chilena se movía "entre la realidad y la superrealidad" y su característica era "su realismo hecho de abstracciones; su glorificación de un hombre, el chileno, a quien hasta ahora no ha podido comprender ni definir del todo, y de un país, Chile, al que a menudo, le vuelve la espalda y del cual no está muy segura de que habrá de sobrevivir"3. (15). Este texto se refiere a la incapacidad de nuestra narrativa para dar cuenta de los procesos sociales y culturales que había experimentado la sociedad chilena a partir de los años treinta, desde que se inicia el proyecto modernizador de las capas medias hasta que se consolida la inserción de Chile en el escenario de la guerra fría, transformándose a fines de los sesenta y comienzos de los setenta en uno de sus frentes más críticos ${ }^{4}$.

La insuficiente "representación de Chile" en su narrativa, se vuelve crítica cuando el golpe de estado obliga a los escritores -consagrados, en

\footnotetext{
${ }^{3}$ Fernando Alegría, Las fronteras del realismo: literatura chilena del siglo $X X$, Santiago de Chile, Editorial Zigzag, 1962.

${ }^{4}$ Cf. Historia de Chile. Desde la invasión incaica hasta nuestros días (1500 - 2000), (Catalonia, 2003), del profesor Armando de Ramón y Chile y la guerra fría global (Instituto de historia P.U.C. y Ril Editores, 2014), editado por los profesores Tanya Harmer y Alfredo Riquelme.
} 
retirada o emergentes- a replantearse sus proyectos literarios y buscar casi "obsesivamente" el o los relatos que permitieran entender aquello con lo que la historia del país nos había sorprendido. Los escritores chilenos se volvieron hacia la historia $\mathrm{y}$, desde muy diversas poéticas, la interrogaron para intentar construir una visión comprensiva de lo que había sucedido.

En 1987, el poeta Raúl Zurita escribió lo siguiente: "El origen de cualquier tragedia es siempre una traición. Vivimos en un país arrasado. ¿Qué traición pesará sobre nosotros?"5. El tono trágico de la declaración, dicha cuando se iniciaba el proceso de transición política desde la dictadura a la democracia, aparecía como una paradoja y se oponía al optimismo incipiente que se respiraba en el país ante la inminente derrota del dictador. Parecía una afirmación, a lo menos, extemporánea. Transcurridos 25 años de democracia, creo que vale la pena examinarla con más profundidad.

Los hechos históricos que siguieron a esas declaraciones ratificaron el optimismo que reinaba en el país. Pinochet fue derrotado en el Plebiscito de 1988 y, un año después, se eligió democráticamente al primer presidente post dictadura. Parecía que los hechos le quitaban pertinencia a la pregunta de Zurita. Sin embargo, este aserto quedó dando vueltas en los pliegues del tramado social y se expresó en parte significativa de la narrativa chilena de los años posteriores (noventa en adelante) y se había anticipado en los anteriores. Se prefiguraba una imagen de Chile como una sociedad que traiciona. La traición funciona en muchas de estas novelas como un motivo estructurador de la ficción literaria de la época. En algunas de las obras más relevantes del período, la referencia directa o indirecta, explícita o implícita a la historia política reciente de Chile, específicamente al golpe de estado y sus antecedentes o consecuencias, se representa como un territorio donde la traición es un hecho, ya sea porque sus protagonistas son traidores en el sentido más literal del término (delatores, soplones, colaboradores) o porque los mundos soñados, deseados o amados, son traicionados por la encrucijada que la historia política de Chile les impuso. Roland Barthes decía que la literatura no era inocente y "que le sabía algo" a la sociedad y a la historia 6 . Creo no equivocarme al señalar que, parafraseando a Barthes, la literatura chilena de estas décadas "le sabía algo a la historia de nuestro país", y ese algo era que entre nosotros habitó la traición.

Si imagináramos un acontecimiento icónico que instala la traición como eje del devenir histórico en Chile, este debiera ser el último discurso de Salvador Allende, que tiene un carácter profético. El palacio de gobierno ha sido bombardeado, Allende sabe que vive el instante mítico de la derrota y, desde la inminencia de su propia muerte -todo indica que ya había tomado

\footnotetext{
${ }^{5}$ Raúl Zurita, La Época, Santiago de Chile, julio 28 de 1987.

${ }^{6} \mathrm{Cf}$. Roland Barthes, El grado cero de la escritura, Siglo XXI Editores, México, 1980
} 
la decisión de suicidarse-, enuncia y proclama el tema de la traición como la frontera que dividirá a los chilenos:

\begin{abstract}
Mis palabras no tienen amargura sino decepción. Que sean ellas el castigo moral para los que han traicionado el juramento que hicieron: soldados de Chile, comandantes en jefe titulares, el almirante Merino, que se ha auto-designado comandante de la Armada, más el señor Mendoza, general rastrero que sólo ayer manifestara su fidelidad y lealtad al Gobierno, y que también se ha autodenominado Director General de carabineros ${ }^{7}$.
\end{abstract}

Allende instituye este momento histórico como un acto de traición. Lo asocia directamente a la ruptura de los militares con el paradigma de las fuerzas armadas constitucionales, sometidas al poder civil. Y esto, en el Chile de esos años, no es un tema menor, ya que la Nación se ufanaba, sin un fundamento muy sólido (eso lo sabemos ahora), de la prescindencia de los militares en política. Cuando se produce el golpe de estado y se rompe el ordenamiento jurídico que había estado vigente desde la Constitución de 1925 (con bastante estabilidad), se defrauda no sólo dicha constitución política sino que también una convicción nacional que -en la medida que se confirmaba en la realidadrepresentaba una seña de identidad. Por lo mismo, se traiciona un modo hacer las cosas, pero también un modo de ser.

$\mathrm{Su}$ texto asume un carácter eminentemente poético. Ya no habla de la contingencia -la derrota de su gobierno está sellada y él avizora un futuro sombrío imposible de revertir a corto plazo-, sino que refiere procesos más profundos y menos evidentes. Su discurso apela mucho más a lo simbólico que a la acción: "Por lo menos mi recuerdo será el de un hombre digno que fue leal con la Patria"". Allende opone de este modo el valor de la lealtad (a la patria, a la Constitución, a sus compatriotas, a sus principios, etc.), a este nuevo tiempo que se inaugura, regido por la traición.

\begin{abstract}
Superarán otros hombres este momento gris y amargo en el que la traición pretende imponerse. [...] Estas son mis últimas palabras y tengo la certeza de que mi sacrificio no será en vano [...], tengo la certeza de que [...] será una lección moral que castigará la felonía, la cobardía y la traición .
\end{abstract}

El discurso de Salvador Allende marca el fin del sistema democrático e inaugura una dictadura que durará diecisiete años. Pero al mismo tiempo, instala un paradigma que funciona en el imaginario nacional como una gran metáfora de las opciones frente a las cuales deberán definirse los chilenos: básicamente,

\footnotetext{
${ }^{7}$ Último Discurso de Salvador Allende en http:/www.ciudadseva.com/textos/otros/ultimodi.htm [Consulta 08.05.2015].

8 Ídem.

9 Ídem.
} 
frente al nuevo escenario histórico, habrá traidores o leales; y las conductas individuales y colectivas deberán ajustarse a este eje. Los militantes optarán por permanecer en Chile o exiliarse; por mantener la militancia o abandonarla; por resistir la represión o confesar y delatar a los compañeros; y los ciudadanos, alejados de la política, deberán decidir si resisten el nuevo modelo social y económico que imponía la dictadura (el neoliberalismo) o simplemente son cooptados por este y se integran al sistema a lomos de su tarjeta de crédito y la compra de bienes en cuotas. Finalmente, los chilenos fuimos conminados a mantener la memoria de nuestros muertos u olvidar para seguir viviendo. Cada una de estas opciones determinaba el lugar que se ocupaba en el eje lealtadtraición.

Creo que la literatura chilena acusó recibo de esta estructura dicotómica, y ficcionalizó el paradigma de representación que propuso Allende: o ser leal a los principios, convicciones, camaradas, amores, etc., o simplemente traicionar. Desde esta perspectiva, es posible realizar una lectura comprensiva de una parte importante de la novela chilena de las últimas décadas. Es lo que intentaremos hacer en este ensayo.

\section{La traición como respuesta a la perplejidad: el caso de Tejas Verdes}

A los meses de haberse producido el golpe militar (1974), el escritor Hernán Valdés escribe el relato testimonial Tejas verdes ${ }^{10}$. Allí narra bajo la forma de un diario de vida su paso por el campo de concentración secreto de Tejas Verdes, lugar emblemático del terror, donde se aplicaron por primera vez los procedimientos de tortura asociados a la DINA ${ }^{11}$. Este texto ha sido leído por la crítica básicamente como un testimonio de denuncia de la violencia. Sin embargo, en algunos episodios muy acotados, cuando los personajes -atónitos frente a la realidad traumática y extraña del campo de concentración-reflexionan sobre lo que ha pasado en el país, el texto se desliza hacia el motivo de la traición. En esas conversaciones se lee la experiencia de la Unidad Popular, en cuanto acontecimiento político, como un proceso traicionado, donde uno de los actores (parte de la dirigencia política de izquierda) compromete al otro actor del drama, los "trabajadores revolucionarios", en una estrategia política que sólo podía conducir a la tragedia. El narrador se pregunta sobre los acontecimientos que condujeron a la derrota del gobierno popular. Está hablando luego de haber

\footnotetext{
${ }^{10}$ Hernán Valdés, Tejas verdes, Barcelona, Editorial Laia, 1978. Todas las citas pertenecen a esta edición.

${ }^{11}$ La DINA (Dirección de Inteligencia Nacional), que dependía directamente de Augusto Pinochet a través del coronel Manuel Sepúlveda, fue el organismo que se instala en 1974 para organizar y ejecutar la represión política de los opositores al régimen dictatorial. Su director fue el comandante del regimiento Tejas Verdes al momento del golpe de estado.
} 
sido torturado y mantenido prisionero durante algo más de un mes, sin expresión de causa, es decir, desde un dolor incomprensible y arbitrario. Es una víctima de la represión. Él se define como un escritor de izquierda no militante. Ha sido seducido por la convicción y utopía marxista de la época y, al mismo tiempo, desde la urgencia por sobrevivir en el campo de concentración, experimenta en forma dramática la certeza de la derrota, con su correspondiente pérdida de la ilusión. Desde ahí, se esboza una acusación implícita de traición dirigida a los máximos conductores del proceso revolucionario chileno:

Hablamos con indignación de los errores y discrepancias internas de la Unidad Popular, de la desinformación en que fueron mantenidos los trabajadores respecto a los planes golpistas y respecto al caos político y de autoridad en que se encontraba el gobierno. ¿Hasta qué punto el temor a la guerra civil, al enfrentamiento armado entre ciertos dirigentes de la Unidad Popular desarmó a los trabajadores y a sus mismos simpatizantes dentro de las fuerzas armadas? ¿Hasta qué punto ese temor facilitó o estimuló la ofensiva reaccionaria? ¿Y hasta qué punto no resultó más caro en vidas humanas -para no hablar de las pérdidas políticas- el golpe de lo que habría costado el riesgo de un enfrentamiento ofensivo contra la reacción, con todas las ventajas que supone tomar la ofensiva? (85).

La crítica se dirige hacia las políticas que sostenía el Partido Comunista y que se expresaba en la consigna "No a la guerra civil", en oposición a las políticas elaboradas por el Partido Socialista que proclamaba "Avanzar sin transar" y, que se alejaba mucho más de la propuesta por el MIR, partido que sostenía la lucha armada y cuyo proyecto se simbolizaba en la proclama "Pueblo, conciencia, fusil"12.

En otro momento, la misma crítica se vuelve a plantear pero se produce un desplazamiento desde lo que era una opinión política racional a un discurso que evidencia las huellas emocionales de la experiencia traumática:

\begin{abstract}
¿Cómo entender lo que pasó en este país? ¿Cómo entender, especialmente, la ingenuidad en que nos mantuvieron, deliberada o inadvertidamente [el destacado es mío], los dirigentes políticos de la izquierda gobernante sobre el verdadero y feroz carácter de la lucha de clases? ¿Cómo fue que gran parte de los conductores de la 'vía chilena al socialismo' conservaron y nos impulsaron a conservar una cierta imagen de 'Fuerzas Armadas profesionales', de una derecha humanista y caballeresca y, en última instancia, de un 'golpe limpio'? ¿Tan poderosa y sutil fue la penetración cultural de la clase dominante, tan persuasiva la proyección de su imagen, incluso entre la izquierda? (104).
\end{abstract}

${ }^{12}$ Las diferencias de estrategia política al interior de la Unidad Popular, muchas veces asociadas a uno de los principales factores del fracaso del gobierno de Salvador Allende, ha sido abordado ampliamente por el historiador Alfredo Riquelme Segovia, en su libro Rojo atardecer. El comunismo chileno entre dictadura y democracia, Santiago, Centro de Investigaciones Diego Barros Arana, 2009, págs. 81-108. 
La recriminación que formula Valdés es, sin riesgo a equivocarnos, "una dura pasada de cuenta" a esa dirigencia política que le hizo creer a los chilenos en el proceso revolucionario de la Unidad Popular. Este proyecto político de la izquierda chilena era heterodoxo respecto a la teoría leninista de la conquista del poder y, particularmente, de lo que postulaban los sectores que se inspiraban en la revolución cubana. Se catalogaba de ingenuidad o francamente de error culposo, imaginar la construcción del socialismo sin una derrota militar de la burguesía. El narrador de Tejas verdes habla desde ese lugar: se representa como el ciudadano que creyó en el proyecto revolucionario a partir de las premisas o promesas que las dirigencias le aseguraron (unas fuerzas armadas constitucionalistas, una derecha democrática, un proceso irreversible a partir de la fuerza del pueblo), y no pudieron cumplir: ni las fuerzas armadas chilenas eran tan leales al ordenamiento jurídico del país, ni la derecha era tan democrática, ni el pueblo tenía las fuerzas necesarias para sostener y defender el proceso revolucionario. Más allá de las discusiones acerca de lo justo o injusto del reproche, hay un gesto recriminatorio hacia la historia social del país, al conceptualizarla como un proceso en el cual los ciudadanos fueron convocados a ser partícipes y en definitiva fueron dejados a la deriva, derrotados y expuestos a lo que el narrador de este testimonio denuncia: el campo de concentración y la tortura. En cierto sentido, esta historia los traicionó.

\section{La gran tragedia de la casa chilena}

La primera gran novela que ofrece una representación total del golpe de estado de 1973 es, en mi opinión, Casa de campo $^{13}$, de José Donoso. Este escritor pertenece a la llamada generación del cincuenta y es, junto a Jorge Edwards, uno de los escritores nacionales que fue parte del mítico "boom" de la novela latinoamericana de los años sesenta. Si bien las estéticas de estos escritores son muy diferentes, hay un par de rasgos que comparten: uno, concebían la novela como la creación de un mundo autónomo y autosuficiente, como una gran metáfora de la realidad; y dos, desafiaron los procedimientos tradicionales de la novela latinoamericana, situándose en el espacio de las vanguardias literarias. A partir de la publicación de El obsceno pájaro de la noche ${ }^{14}$, Donoso es reconocido como un novelista que se ubica en la primera línea de la creación narrativa en el continente y es percibido como uno de los exponentes de este movimiento que encarna con mayor propiedad la idea de escribir una novela total.

\footnotetext{
13 José Donoso, Casa de campo, Barcelona, Seix Barral, 1978. Todas las citas corresponden a esta edición.

14 José Donoso publica esta novela el año 1970 y es, en ese momento, su obra de mayor resonancia a nivel internacional.
}

Araucaria. Revista Iberoamericana de Filosofía, Política y Humanidades, año 17, n 34. Segundo semestre de 2015. Pp. 303-327. ISSN 1575-6823 e-ISSN 2340-2199 doi: 10.12795/araucaria.2015.i34.14 
El golpe de estado lo sorprende en el extranjero y allí escribe Casa de campo. Esta novela puede entenderse como una novela referida a la historia de Chile y su contingencia inmediata. Esto lo certifica el propio Donoso, en una entrevista que le concede a la crítica Nelly Martínez, a propósito de la publicación de la novela ${ }^{15}$ :

En el momento en que a mi país lo estaban capando...sentí que yo tendría que levantar algo, una especie de polvareda. Realmente me indignó (me indigna) la brutalidad de la represión (72).

Y agrega, al explicitarle a la entrevistadora que concibió la novela como una alegoría histórica, lo siguiente:

Representa primordialmente el deseo de libertad, la tentativa de libertad que hay en ciertos seres ya que todo ser humano tiene derecho a ella. Algo que lo establecido -lo establecido, no una clase social- se lo niega. En este caso lo establecido son los poderes políticos aceptados, los monopolios extranjeros: dicho pronto y rápido los Estados Unidos (73).

En un notable ensayo ${ }^{16}$, el escritor Carlos Cerda recupera una cita de otra entrevista que se le hace al novelista, y que confirma lo que afirmamos. A propósito de si el lenguaje chileno de la novela es intencional o no, la respuesta de Donoso es concluyente:

Es totalmente intencional. Es decir, este libro se trata de Chile, pareciera que estoy hablando de otra cosa, pero estoy hablando de Chile (72).

Dicho en otros términos, aunque Casa de campo es una novela escrita bajo la forma de una alegoría y con un alto componente de irrealidad, la relación con la historia de Chile (incluso de América latina) es indiscutible, lo que le permite a Carlos Cerda sostener lo siguiente:

Están [en Casa de campo] todos los motivos anteriores, todas las "formas" donosianas que preceden al nacimiento de una nueva idea artística, pero esta vez potenciadas por el carácter parabólico de la idea, por el intento de escribir una novela que aluda metafóricamente a la sociedad chilena, a "la realidad nuestra”, para usar la expresión del propio Donoso (86).

En esta novela, a través del mecanismo de la irrealización de la realidad ${ }^{17}$, Donoso intenta representar el golpe de estado como parte de una realidad mayor, con más pliegues y zonas oscuras que conectan distintos niveles de

${ }^{15}$ Cf. Nelly Martínez, Entrevista, "Hispanoamérica", nº 21 (1978), p. 72.

${ }^{16}$ Cfr. Carlos Cerda, José Donoso: originales y metáforas, Santiago de Chile, Planeta, 1988.

17 Para profundizar en este tema, revisar el libro de Carlos Cerda ya citado. 
realidad: lo político, lo social, lo cultural. En la novela se cuenta la historia de la familia Ventura (familia oligárquica que vive de la explotación de las minas descubiertas en sus tierras). La acción transcurre durante un verano en la casa de campo, a la cual va toda la familia a pasar las vacaciones. En esta casa, el mundo está ordenado en, al menos, tres estamentos: los grandes (que detentan el poder), los niños (que son los dominados hasta que crecen y se integran al mundo de los grandes) y los lacayos (que sirven a los grandes y reprimen a los niños para preservar el orden). Existen, además, los antropófagos, nativos del lugar a quienes se le atribuye una alta peligrosidad y representan una amenaza para el orden instaurado en esta micro-sociedad que es la casa de campo, y que justifica la protección de la familia en una gran propiedad enrejada.

Los acontecimientos cruciales de la novela se desencadenan cuando los adultos deciden realizar una excursión por el día, sin los niños. Sin embargo, para estos últimos, la excursión durará doce meses, el tiempo suficiente que les permite tomar el control de la casa. Conducidos por el tío Adriano Gomarra, médico que la familia había encerrado por loco y los niños liberan (sus iniciales se corresponderían con las de "Allende Gossens"), producen una verdadera revolución, alterando en forma radical el orden establecido: se levantan las rejas que limitan el mundo de los Ventura y el de los aborígenes/antropófagos, se redistribuye la riqueza, se liberan las conductas sexuales, etc., etc. La imagen de un lugar donde se instaura el caos en oposición al régimen de orden "original" aparece como una representación alegórica de la visión que la derecha política en Chile tuvo de la gestión del gobierno de Salvador Allende:

Reinaba el desorden, la insatisfacción, la hambruna, la pereza. Las vituallas de la despensa fueron repartidas a tontas y a locas [...]. Los nativos [...] ya no trabajaban porque no tenían a quien vendérselo.[...] Lo peor era que el desconcierto y el miedo habían producido un caos en que los distintos grupos integrados por niños y nativos luchaban unos contra otros o trataban de hacerse la vida imposible (258).

Esta descripción de la situación en la casa de campo es tributaria, sin lugar a dudas, del discurso que la derecha desplegó para minar y derrotar al gobierno de la Unidad Popular. Caos, hambre, destrucción del aparato productivo, una lucha intestina, desabastecimiento, pérdida del sentido de autoridad, todas expresiones que estaban en los discursos y proclamas que se lanzaban contra el gobierno en los años 1970-1973. Donoso los recoge y los integra a su texto. Es precisamente este discurso el argumento que convence a los adultos de que deben actuar para recuperar su posición y restituir el orden natural de las cosas. Y al igual que con la Unidad Popular, el proceso emancipador de niños y nativos terminará con una serie de hechos que conforman una alegoría casi 
perfecta de lo que fue el golpe de $\operatorname{estado}^{18}$. Pero la restauración del orden no será un volver a un cierto pasado más o menos idílico. Muy por el contrario, los Ventura hipotecan en los lacayos "el trabajo sucio" para poner fin a este juego de niños que fue la toma de la casa. Para esto se valdrán de todos los mecanismos, incluidos la tortura, muerte y desaparición de sus propios hijos. Un episodio refleja de manera dramática lo que estamos diciendo:

Cuando por fin [sus padres] lograron que Fabio y Casilda confesaran que sí, que los antropófagos preparaban un ataque, que ellos y todos los niños de la casa comían carne humana, que se trataba de un levantamiento de las brutales masas ignorantes, los ataron y los amordazaron entre los gritos de Fabio y Casilda implorando que hicieran lo que quisieran con ellos pero que no los separaran (260).

Y el narrador sentencia: "Es mejor que mis lectores se enteren inmediatamente que nunca nadie supo nada más de ellos." (260). Las coordenadas para el desenlace trágico comienzan a establecerse como inevitables en la novela. Para los adultos de la familia, se vuelve imperioso restituir las cosas a su lugar:

¿Cómo impedir que salieran rumores de lo que allá sucedía, que en todo sentido estropearían la reputación de la familia? ¿Cómo defender las leyes por ellos implantadas? ¿Cómo constituirse en paladines del orden? La respuesta no podía ser más que una: la violencia (265).

Sin embargo, los Ventura, portadores de una cierta civilidad culta, racional y pacífica, no pueden mancharse las manos con la violencia. Para ello, acuden a sus lacayos que, en la novela, funcionan como un escuadrón militar:

Ustedes deben mantenerse con las manos limpias para dar ejemplo sin el cual no hay orden -dice uno de los lacayos-. Para ensuciarnos las manos estamos nosotros, los sirvientes: una tropa vigorosa, disciplinada, que acepta la autoridad absoluta del Mayordomo (267).

Aparece aquí la figura del Mayordomo, una representación clara del dictador que ejercerá el poder con absoluta impunidad. Los Ventura quedan:

Hipnotizados por esa figura fulgurante creada por ellos mismos, que [...] parecía más gigantesca, más poderosa, más brutal que la de todos los Mayordomos anteriores, y cuyo rostro individual les sería ahora imposible de olvidar (273).

${ }^{18}$ En el libro de Carlos Cerda al que nos hemos referido se analiza y demuestra con detalle el proceso de conformación de la alegoría histórica. 
Y el término "hipnotizados", en este contexto, adquiere la significación de "entregados", “desposeídos", “derrotados", etc. El poder queda, inequívocamente en manos de este Mayordomo singular mientras ellos sólo mantendrán una fortuna, las minas, que venderán en algún momento a los extranjeros de pelo colorado. "Los Ventura ya no sabían qué iba a ser, porque ahora todo quedaba en manos del Mayordomo" (275).

La gran traición se ha consumado: esta oligarquía chilena, esta derecha política, ha hipotecado sus valores, su orden original, por el dominio de una dictadura que en todo se opone al modelo de sociedad que ellos creían sostener. Han, de alguna forma, entregado el sistema de ordenamiento político-social tradicional, identificado con el régimen oligárquico chileno del siglo XX, para salvar su riqueza y su sobrevivencia económica.

José Donoso establece un discurso literario donde la realidad políticahistórica de nuestro país, catalizada por el golpe de estado de 1973, se representa como el corolario de un proceso de desintegración del orden que, para ser restaurado, debe reinstalarse mediante la violencia. Pero esto es una ilusión, porque el viejo orden ha sido desplazado $y$, traicionando los viejos valores que inspiran la vida en el país, irrumpe y se instala un nuevo modelo de sociedad, de carácter dictatorial. En este sentido, la representación de la realidad nacional propuesta por el discurso literario de José Donoso está en consonancia con el paradigma propuesto por Allende: nuestra sociedad estará atravesada por la traición a su propia naturaleza y tradición.

\section{Historias en tono menor, pequeñas traiciones}

Algunos años después, en su novela El jardín de al lado, ${ }^{19}$ Donoso realizará un giro muy interesante, que valida la hipótesis del profesor Mario Lillo, cuando postula que en Chile el golpe de estado no ha generado una gran novela de la dictadura sino que la irrupción de la historia reciente se ha hecho de modo fragmentario, en distintos procesos creativos, ninguno de los cuales alcanza a configurar una imagen global de lo que fue, en definitiva, este período. Lillo observa este fenómeno, desde lo literario, como una reacción al proyecto de novela total que los escritores del boom enarbolaron en los años 60 (al cual ya hemos hecho referencia):

En oposición [...] a la aseveración de quienes lamentan la ausencia de un texto que narre desde una visión total las circunstancias personales y sociales del último cuarto de siglo chileno, $[. .$.$] el relato de los acontecimientos posteriores$ a 1973 se ha verificado no en una gran novela total sino a través de múltiples

\footnotetext{
19 José Donoso, El jardín de al lado, Barcelona, Seix Barral, 1981. Todas las citas corresponden a esta edición.
}

Araucaria. Revista Iberoamericana de Filosofía, Política y Humanidades, año 17, n⿳ 34. Segundo semestre de 2015. Pp. 303-327. ISSN 1575-6823 e-ISSN 2340-2199 doi: 10.12795/araucaria.2015.i34.14 
novelas que -en el espíritu de la posmodernidad- dan cuenta de temas, sujetos, espacios, tiempos o destinos de modo parcial, fragmentario, atomizado, desperfilado $^{20}$.

Esta mirada nos parece pertinente, ya que pone de manifiesto el hecho de que la gran ruptura de Chile con su pasado democrático y constitucional, se alinea con un fenómeno de mayor envergadura que dice relación con la globalización del capitalismo neoliberal y la decadencia de las grandes concepciones del devenir histórico, fenómenos que debilitan sin duda la experiencia colectiva consciente y, de alguna forma, las nuevas reglas del poder son naturalizadas y se viven desde una óptica individual y fragmentaria.

La tragedia del pseudo-protagonista de El jardín de al lado es que está obsesionado con escribir -a partir de su experiencia en la prisión (una semana en la que ni siquiera fue torturado pero que fue suficiente para optar por el autoexilio)- la gran novela de la dictadura, pero no logra avanzar en su escritura. Se siente desautorizado para dar cuenta de una tragedia que, en definitiva, no vivió de verdad. "No nací para héroe, ni siquiera para tener razón" (116), dice el protagonista como corolario de su impotencia:

\begin{abstract}
Al avanzar por mi copioso escrito se me fue haciendo indudable que la pasión que pretendía animarlo no era convincente como literatura ni válida como experiencia. Desde aquí, lejos en el espacio y en el tiempo, los "buenos" no siguen siendo tan totalmente buenos como al principio lo sostuvimos, cuando algunos, no yo, arriesgaron o perdieron la vida por ello... ¿Y los "malos" -tiemblo ante mi blasfemia al proponerme esta pregunta tal vez traidora- fueron, o son, tan totalmente malos? (115).
\end{abstract}

En alguna parte de él mismo, se siente un impostor. Ha comenzado a dudar de sus convicciones, del sentido de su historia y de la Historia, del lugar que ocupa entre los buenos y los malos, y de sus propias certezas respecto de lo que es bueno y es malo. Hay en el fondo de su debate interno un sentimiento de traición, no muy grande pero determinante, que no logra enunciar y que lo enmudece. Él no debería estar en el exilio sino en el interior del país, exponiéndose a una experiencia verdaderamente traumática. Esta es una traición pequeña, que incluso es difícil considerarla como tal. Pero lo relevante acá no es la naturaleza "objetiva" de sus acciones, sino el modo en que ellas se inscriben en un paradigma lealtad/traición que ha ido permeando todos los niveles de significación. Él no ha traicionado, no delató a nadie, ni siquiera fue apremiado. Pero pasar por esa zona de horror (la de las detenciones ilegales y clandestinas, la tortura y las desapariciones) y salir indemne, es suficiente como para vivir la experiencia bajo sospecha. Simplemente exiliarse, porque

${ }^{20}$ Mario Lillo, La novela de la dictadura en Chile, "Alpha”, n²9, diciembre 2009, p. 43. 
no se toleraba el país o se tenía miedo, podía leerse como un gesto de traición, suficiente como para inhabilitar la escritura.

Con esta propuesta, Donoso abandona el proyecto literario que hegemonizó la década del 60 -el de la escritura de una novela total- modelo que rige su primera aproximación a la tematización directa de la historia en su novelística a través de Casa de campo-, y se suma a los intentos fragmentarios por representar lo que ha sido la historia política de Chile durante los últimos 50 años, período marcado definitivamente por el fracaso del proyecto revolucionario de la Unidad Popular y la imposición del modelo neoliberal a través de un golpe de estado y la vigencia de una dictadura férrea durante diecisiete años.

\section{La novela bajo la dictadura}

Pertenezco a la generación de los ochenta, categoría con la que algunos autores identifican a los escritores y poetas que nos desarrollamos literariamente bajo la dictadura ${ }^{21}$. Crecimos en un espacio que, a las carencias cívicas básicas por todos conocidas (vivíamos sin estado de derecho y sin las libertades mínimas), se le agregaba una carencia de soporte cultural enorme. Al interior del país, la literatura chilena estaba sometida a condiciones extremadamente difíciles de producción (la censura operaba plenamente) y de distribución de libros (un mercado editorial precarizado). El golpe de estado y la dictadura misma eran temas literarios clandestinos o, si se aspiraba a que los libros fueran publicados, eran temas desarrollados en una especie de "escritura de lo no dicho”, como señaló el poeta Raúl Zurita alguna vez. Al respecto, la crítico Adriana Valdés describe este fenómeno con singular precisión:

En un momento de insuficiencia de la representación, de fenómenos sociales que parecían darse más allá y más acá de los discursos hechos para analizarlos y explicarlos, [las obras de artes, incluida la literatura] proponían imágenes que exigían segunda y tercera lectura; proponían inscripciones a veces crípticas, con algo de escritura de catacumbas ${ }^{22}$ (69).

Y agrega que estas condiciones de producción artísticas, a la larga, hicieron que la capacidad del lenguaje del arte para "referirse directamente a las cosas [fuera] disminuyendo a medida que aumentaba la vulnerabilidad" (71). La literatura bajo la dictadura es un proceso fuertemente marcado por su

\footnotetext{
${ }^{21}$ Esta categorización se propone en las introducciones que los escritores Diego Muñoz Valenzuela y Ramón Díaz Eterovic hicieran para las antologías de cuentos Contando el cuento (Santiago de Chile, Editorial Sinfronteras, 1986) y Andar con cuentos (Santiago de Chile, Mosquito Editores, 1992).

${ }_{22}$ Adriana Valdés, Una historia de miedo: cultura, autoritarismo, democratización, [en Valdés, Adriana, Composición de lugar. Escritos sobre cultura, Santiago de Chile, Editorial Universitaria, 1996].
} 
condición de apremio, y por lo tanto, sólo puede leerse teniendo presentes esas condiciones y, como dice Adriana Valdés, disponiendo de un lector cómplice, sagaz y esforzado:

Las obras de las que estoy hablando tienen por característica el exigir un esfuerzo al espectador, un esfuerzo que, fuera de las circunstancias en que se produjeron -desde esta circunstancia actual y desde este país-, puede resultar muy fuerte y muy abusivo. Son obras de situación, obras situadas, hasta sitiadas, podría decirse. La situación de su producción está escrita en ellas (71-72).

Escribir en tiempos de dictadura en Chile era enfrentarse a la imposibilidad de la palabra. Los escritores teníamos que inventarnos un lenguaje que, al final, dependía de la capacidad del lector para su plena realización; o al menos, para su plena realización en cuanto obra literaria que quiere escribir la historia, aunque sea bajo la forma de la denuncia o el grito de protesta. Eran textos que traicionaban la naturaleza primera del lenguaje, porque la historia a la que remitían era innombrable. En la literatura, el efecto fue clave: escritura fragmentaria, relatos múltiples, verdades a medias, orfandad en todas partes, desamparo. Y la traición que se instala en los relatos como un telón de fondo o, en algunos casos, se hace protagonista.

\section{Encierro y traición en Diamela Eltit}

Diamela Eltit es una de las escritoras que comienza su trabajo creativo en plena dictadura y quien desarrolla una de las poéticas más singular e innovadora del período. Su lenguaje narrativo es una palabra rota, fragmentada, producto de una ruptura sólo comparable a las rupturas de la historia y las vidas en Chile. En su segunda novela, Por la patria ${ }^{23}$, se cuenta la historia de Coya, una mujer que habita una zona marginal de una ciudad, un territorio asolado por la violencia que se representa como una especie de prostíbulo. Rodrigo Cánovas ${ }^{24}$ los define como un espacio artificial que bien podría ser el hogar, una casa cualquiera o el propio país: "[En la novela Por la patria] la dictadura chilena aparece actuada en las relaciones de abuso y sumisión en la pareja, dentro de un espacio cerrado". (178).

Este lugar es violentado por los militares. Las mujeres serán sometidas a prácticas de tortura y serán vulnerados sus derechos. Esta imagen es la representación de un territorio oprimido y opresivo, donde las esperanzas se van desmontando sistemáticamente. $\mathrm{Y}$ es en medio de este espacio, donde

\footnotetext{
${ }^{23}$ Diamela Eltit, Por la patria, Santiago de Chile, Seix Barral, 1986.

${ }^{24}$ Cf. Rodrigo Cánovas, Colofón chileno [en Cánovas, Rodrigo, Sexualidad y cultura en la novela hispanoamericana, Santiago de Chile, LOM Ediciones, 2003].
} 
Coya toma conciencia de que ha sido traicionada. Ella y todas las mujeres. Y esa delación se ha gestado en el centro mismo de su intimidad. El delator, Juan, es su amante. No sólo la entrega a la policía militarizada, sino que se trasforma en su torturador y carcelero. Cánovas describe este personaje en los siguientes términos: "Juan -débil, cobarde, traidor e, incluso, sin grandes dotes eróticos". (178).

En el centro de la historia, la figura de este hombre se vuelve polisémica, en cuanto representa el poder dictatorial, pero también la opresión histórica que se ha ejercido sobre lo femenino en cuanto género. El mundo representado en la novela es un territorio de traición y, de alguna forma, remite a las decenas de casos de organizaciones infiltradas, antes del golpe de estado, y que se develaron inmediatamente después de ocurrido este. Hay un caso emblemático de este componente que se introduce en el imaginario nacional, representado por el "Guatón” Romo, un dirigente poblacional del MIR que, al día siguiente del golpe de estado, se transformó en un activo persecutor y torturador de sus ex camaradas ${ }^{25}$.

Si bien Por la patria es probablemente más una novela de la violencia y el encierro, que se propone como una metáfora total de lo que era Chile bajo dictadura, tiene en el centro desencadenante del relato, un brutal acto de traición. ¿Qué se ha traicionado? El amor, el deseo, el cuerpo. Las mujeres encabezadas por Coya resistirán y la mácula caerá sobre el traidor, del mismo modo como cayó sobre los generales traidores.

Varias décadas después de haberse publicado Por la patria, con un país que abandonó la dictadura y una democracia que ya tenía una década de vida, Eltit publica Jamás el fuego nunca ${ }^{26}$, donde relata la historia de dos militantes, posiblemente comunistas ya que tienen La Internacional ${ }^{27}$ como himno. La pareja está encerrada en una pieza. Representan la ruina de múltiples células (políticas u orgánicas, expresión ambivalente por cuanto las organizaciones de base del Partido Comunista en Chile se denominaban así) que se han ido deteriorando y muriendo a lo largo de la década, siglo o milenio. Aunque el eje temporal es incierto e intencionalmente ambiguo, se puede leer que estamos enfrentados a la historia del siglo XX y sus discursos revolucionarios y utópicos, y también a las estrategias políticas mediante las cuales los partidos de izquierda enfrentaron a la dictadura en nuestro país. Comparto, en este sentido, lo señalado por José Antonio Rivera ${ }^{28}$ cuando apareció esta novela:

\footnotetext{
${ }^{25}$ Cf. Manuel Salazar, Las letras del horror. Tomo I: La DINA, Santiago de Chile, LOM Ediciones, 2011.

${ }^{26}$ Diamela Eltit, Jamás el fuego nunca, Santiago de Chile, Seix Barral, 2011. Todas las citas corresponden a esta edición.

${ }^{27} \mathrm{La}$ Internacional es el himno que entonaban los partidos comunistas miembros asociados a la, precisamente, Internacional Comunista o Tercera Internacional.

${ }_{28}$ José Antonio Rivera Soto, La muerte del tiempo utópico en Jamás el fuego nunca de Diamela Eltit, "Acta literaria", n 39 (2009).
} 
La historia narrada visibiliza los excesos dictatoriales y una lucha ideológica de las que ahora no son más que residuos. Porque las condiciones políticas de enunciación son las actuales: han caído los socialismos reales, la globalización campea y para aquellos que vivieron en y para las utopías, sólo queda una retórica de la decepción (125).

La novela comienza con el relato de la mujer militante (que narra en primera persona) y que establece el momento en que ella es acusada de "estalinista" y él, el dirigente de mayor jerarquía, la defrauda por primera vez:

Hube de vislumbrar en tu mirada un atisbo de inquietud mezclado con clara decepción. Una primera, incipiente, inexcusable mirada de abandono o de un rencor material (13-14).

De ahí en adelante, el relato de la protagonista construye el mundo como si fuera un gran cuerpo donde se mueven las "células", y se hacen "organismo", y donde cada militante está integrado y es, él mismo, una célula. Es la historia de la experiencia militante que tanto podría habérsele aplicado a los recios bolcheviques de comienzos del siglo XX o a los sencillos militantes comunistas, como el Lucho, de Rancagua, que ante su detención y tortura, prefiere el suicidio. Se afirma la historia mítica, férreamente ideológica, que hace que los militantes se vean a sí mismo como dueños de una verdad intransable:

A pesar que el tiempo no cesa de transcurrir, nunca, vivimos como militantes, austeros, concentrados en nuestros principios. Pensamos como militantes. Estamos convencidos de que nuestra ética es la única pertinente [...] Sabemos que la historia terminará por darnos la razón (28).

Sin embargo la novela se cuenta desde la ruina, desde un lugar donde ya nada es y sólo se ha instalado la muerte. Esto queda fijado desde el comienzo cuando la protagonista ha sido acusada y sentenciada de estalinista, al interior de la célula, por oponerse al giro reformista que su pareja pregona para el tiempo que viene (posiblemente, los años finales de la dictadura y comienzo de la democracia), y de esta forma caer en una política que "podía aniquilar los presagios de un siglo que terminó sin pena ni gloria, sin gloria, especialmente así, cautivo en su propio conformismo, incluso tú, que parecías incorruptible"(24). Definitivamente, esta es la historia de las sucesivas traiciones a una idea, a una imagen de mundo, a una cierta ética de la política: la de los movimientos revolucionarios del siglo XX. Y lo que queda al final del camino, es un nuevo siglo "que no nos pertenece y que, sin embargo, estamos obligados a experimentar y en este siglo parece todo irreal o prescindible" (23), porque como dice José Antonio Rivera, "el tiempo se hace ambiguo, confuso, porque el acontecer de la historia ha dejado de regirse 
según los presupuestos marxistas, y los personajes se encuentran presos de ese desajuste esencial" (126).

En el fondo de este proceso, donde la experiencia histórica se mira desde una profunda decepción, están las traiciones. Pero no sólo la política o ideológica. También están las traiciones por debilidad frente al enemigo:

Te reías y te reías porque ya sabías o entendías o presagiabas que estábamos perdidos, que nuestra célula, la última, estaba por naufragar ante los imperativos de lo que tanto temíamos, la historia [...] Te reías en los momentos en que había caído completa la postrera dirección del partido, te reías cuando la infiltración era incontrarrestable (103).

Este es el relato de la represión y de sus efectos internos. Cuando la protagonista habla de su "estado" y lo asocia al terror, podemos pensar en la persecución y las torturas; pero también podemos pensar en el embarazo, aquel que conducirá en cierto sentido a la gran traición: su muerte y la del niño.

Es interesante ver cómo el motivo de la traición, que es secundario en Por la patria, ya en esta novela -que observa desde el siglo XXI-, atraviesa toda la historia como un gran eje estructural.

\section{Infiltrados y soplones: la doble cara de la traición}

Hay dos novelas publicadas a fines de los años ochenta que son interesantes de revisar. Se trata de El infiltrado (1989) de Jaime Collyer ${ }^{29}$ y Santiago 0 (1989), de Carlos Franz ${ }^{30}$.

En la primera de ellas, publicada por primera vez en 1989, Collyer cuenta la historia de Fabres, un joven desempleado, con un matrimonio en banca rota, que postula a una agencia de dudosa naturaleza, encargada de hacer informes para el Ministro de la Vivienda de la dictadura. Este trabajo se simboliza como trabajar con el enemigo. Su mujer, Natalia, se lo enrostra cuando le pregunta de qué se trata su nuevo empleo. Ante la ambigua respuesta de Fabres, ella concluirá que "Parece algo oficial" (33) y acto seguido lo incrimina: "Esto parece un arsenal propagandístico -comentó con un asomo de asco en la voz. Vas a trabajar para el ministro Goebbels" (33).

Esta acusación no es trivial, puesto que su mujer es hija de un asesinado por la dictadura. Por lo mismo, aceptar ese trabajo lo coloca en la línea de los traidores. Y Natalia no pareciera estar equivocada, ya que Morán, el dueño de

\footnotetext{
29 Jaime Collyer. El infiltrado, Santiago de Chile, Editorial Sudamericana, 1996. Todas las citas corresponden a esta edición.

${ }^{30}$ Carlos Franz, Santiago 0. Santiago de Chile, Aguilar chilena de Ediciones, 2008. Todas las citas corresponden a esta edición.
} 
la agencia, podría definirse como un mercenario. En un almuerzo con su nuevo empleado, lo explicita:

- Sé lo que piensa [...] Un mercenario.

- ¿Perdón?

- Piensa usted que soy un mercenario. (46)

Morán está instalado en el cinismo más absoluto, más allá de cualquier ética, excepto la de vivir su vida. Fabres reflexiona: "La crudeza del apelativo logró desconcertarme. ¿Era eso entonces, un oscuro asalariado del poder, dispuesto a legitimar en informes de más que dudosa veracidad la torpeza de quienes lo detentaban?" (46) Y su relación con esa agencia irá comprometiéndolo cada vez más. Los informes serán cada vez más críticos, al punto de llegar a redactar un informe para un manual de tortura.

Por su parte, Natalia es un combatiente literalmente de armas tomar. Su ética de la militancia es absoluta, movida por una necesidad de vengar la muerte de su padre y restaurar la justicia. Sin embargo, en ese proyecto quedan heridos y contusos. Se enamora de un camarada y, una vez descubierta la relación, termina por abandonar a Fabres. Una nueva traición ingresa al escenario y no será la última. Gastón, el amante de Natalia, se salvará en una acción de propaganda directa, a costa de Natalia. Una vida por otra.

Toda la novela trasunta una realidad de dobleces y encubrimientos, como si todos estuviesen infiltrados en el enemigo. El narrador se instala definitivamente en la negación de una historia que ya lo ha negado a él, a Natalia, a Gastón y al propio Morán. Su reflexión es dramática:

La historia no se detenía, en su derrotero indefectible hacia ninguna parte. Un camión basurero la historia, sorbiendo cada tanto, entre sus fauces de hierro, a sus protagonistas, por mero afán de romperles las costillas o arrojarlos de vuelta con un agujero en el pecho (179).

En una línea muy similar podemos leer Santiago 0, la primera novela de Carlos Franz (1989). En ella se cuenta, de modo lateral, la historia de un soplón, de un muchacho que por amor sacrifica a un amigo, convirtiéndose en agente de una sección especial de la policía llamada precisamente Santiago 0. La novela se construye a partir de pequeñas y ambiguas trazas y en un tramado de voces donde los roles tienden a confundirse. Es una época de murmullos, rumores, lugares secretos y muchos secretos. Y un amor desairado e incontenible, que lleva al protagonista a traicionar sus amistades, su grupo de referencia y su propia amada. La historia lo convertirá en otra persona. En este sentido, el epígrafe es muy revelador: "Yo no soy yo; / tú no eres él o ella; / ellos no son ellos." (8) Esta es una historia de transformaciones y trampas, donde nadie en 
definitiva es leal a su propio destino. La visión final del narrador es patética: "En sólo siete años sucediste a Blanco [el oficial que lo reclutó]. Eliminándolo llegaste a la cúspide del escalafón." (137).

El historiador Alfredo Jocelyn-Holt, contemporáneo de nuestra generación, en el posfacio de la edición que hemos referido, sintetiza el ethos de este texto, y de buena parte de la novela escrita en Chile durante la dictadura:

La nuestra [...] fue la primera generación chilena que habría de desengañarse a concho, volverse adulta ya en plena desilusión [...] No nos correspondió ni la épica de la esperanza utópica ni el aporreo violento que traería su posterior colapso y derrota. [...] Nos sabíamos huérfanos. De historia, de progenitores, de modelos. La historia era algo que ocurría definitivamente en otra parte (153).

Hay un detalle revelador: el relato ocurre en torno a un lugar emblemático de la ciudad de Santiago: la Escuela de Derecho de la Universidad de Chile. Allí se teje esta historia sin historia, esta historia que abandona y traiciona a sus protagonistas dejándolos huérfanos y sin sentido. Ya nadie es el que iba a ser. Todos han mudado, se han transformado, han traicionado.

\section{La traición a la memoria: el olvido}

El tema de la memoria y el olvido, pareciera estar cruzado también por el eje lealtad-traición. La reconstitución democrática durante la década del 90, se desarrolló bajo el concepto de "democracia de los acuerdos" -o consensos-, entre la derecha política (herederos de la dictadura) y la coalición de centro izquierda, Concertación por la democracia, que había conquistado el gobierno y se propuso hacer los cambios democráticos, "en la medida de lo posible" 31 , evitando los conflictos de alta intensidad. Pero este proceso tuvo efectos no deseados, que Nelly Richard ${ }^{32}$, académica chilena, releva:

[Los gobiernos democráticos quisieron] desacentuar las marcas de ese pasado; atenuar los énfasis de toda oposición para nivelar tonos e inflexiones y reunir voces en discordia bajo la misma consigna moderadora de la prudencia y de la resignación; desintensificar el valor de experiencia contenido en la dramática del pasado para traducir sus datos al lenguaje notificante del informe y del reportaje de actualidad (9-10).

${ }^{31}$ Frase que alude a la expresión utilizada por el primer presidente electo postdictadura, don Patricio Aylwin Azócar, para caracterizar la política de su gobierno.

32 Nelly, Richard, Presentación [en Nelly Richard, ed.: Politicas y estéticas de la memoria, Santiago de Chile, Editorial Cuarto Propio, 2000]. 
El resultado de esta estrategia política habría sido una cierta forma de abordar los temas de la memoria del trauma social que más bien escamoteó o retardó el abordaje de los relatos más crudos y difíciles de aceptar de lo que había sido la experiencia chilena reciente.

El formulismo y el tecnicismo del consenso frustraron así una manera -necesariamente polémica- de hacer memoria, que requiere del examen crítico de los antagonismos de posiciones que dividen el sentido de la historia con sus conflictivas batallas de interpretación y legitimidad (10).

Dicho de otro modo, se impuso una cierta memoria oficial, acotada y débil respecto a lo que habíamos vivido. En este punto, el tema de la memoria, es decir, la apropiación del recuerdo desde un presente que nos interesaba plasmar como memoria colectiva, se hizo mucho más problemático. Beatriz Sarlo ${ }^{33}$ lo plantea en los siguientes términos:

El campo de la memoria es un campo de conflictos que tienen lugar entre quienes mantienen el recuerdo de los crímenes de estado y quienes proponen pasar a otra etapa, cerrando el caso monstruoso de nuestra historia (24).

No era fácil abordar los temas más duros del pasado. El escritor Marco Antonio de la Parra ${ }^{34}$ refleja muy bien este proceso, en cuanto plantea que no bastaba simplemente con recordar, que este acto era sólo una fase de la construcción de la memoria. Después de eso, quedaba todo por delante:

La memoria no es el aprendizaje. La memoria es la condición humana. [...] La posibilidad de verse en la flecha del tiempo, la propia y la de su sociedad, la del día y la de la vida y la de la historia (231).

En esta mirada, el tema del olvido aparece como central. Para la construcción de la memoria, de una que permita un relato hacia el futuro, es clave determinar cuánto olvidar. De la Parra lo propone de la siguiente forma: “¿Cuánto olvidar? / Lo que nos salve del pozo negro de la ira. Lo que nos salve del pozo negro de la melancolía de fango. Todo aquello que niega la complejidad de la vida. / ¿Cuánto recordar? / Todo lo necesario para rescatar el relieve de los asuntos, las dimensiones múltiples de nuestra situación en el mapa." (231)

A partir del año noventa en Chile, el tema de la memoria aparece como recurrente en muchas novelas. Para los efectos de este ensayo, considero aquellas que significan el olvido como una forma de traición. Textos relevantes

\footnotetext{
${ }^{33}$ Beatriz Sarlo, Tiempo pasado, Buenos Aires, Siglo XXI Editores, 2007.

${ }^{34}$ Marco Antonio de la Parra, Memoria y olvido [en Nelly Richard, ed.: Políticas y estéticas de la memoria, Santiago de Chile, Editorial Cuarto Propio, 2000].
} 
en esta mirada son novelas como Cien pájaros volando de Jaime Collyer; El desierto, de Carlos Franz; Los años de la serpiente, de mi autoría; La vida doble, de Arturo Fontaine; Carne de perra, de Fátima Sime; y La burla del tiempo, de Mauricio Electorat, entre otras.

Pero hay dos novelas que me parecen especialmente interesantes: Bosque quemado del escritor Roberto Brodsky ${ }^{35}$ y Estrellas muertas (Alfaguara, Santiago, 2010) de Álvaro Bisama ${ }^{36}$.

En Bosque quemado se cuenta la historia de un hijo grande, padre de familia y divorciado, que acoge en su casa a su padre de más de 70 años, cuando este viene saliendo de una postrera y terminal historia amorosa. Este es el último fracaso del padre, que se suma a una historia de fracasos. El hijo lo dice de la siguiente forma: "Éramos los primeros náufragos de un mundo que al día siguiente sucumbiría por completo, guías aventajados de la colectividad" (44). Moisés -hijo de inmigrantes judíos europeos-sufre a lo menos un doble fracaso: primero, el de su proyecto de familia, ya que su mujer lo traiciona con otro hombre y lo abandona; además, sufre la pérdida de su patria (Chile), ya que siendo médico, judío, militante comunista y funcionario del gobierno de Allende, debe exiliarse. Al final, la historia lo olvidará (en su país ya nadie se acordará de él) y el olvido lo derrotará. Este padre, que había labrado su posición desde la escuela pública y la universidad estatal, que apostó por un proyecto revolucionario para prestar sus servicios a los demás, termina totalmente derrotado y expuesto, posiblemente, a la peor de todas las derrotas, que es la ruptura del vínculo con su propia historia. Sufre un trastorno severo de la memoria. "Bosque quemado" es la expresión que en la novela utiliza un médico geriatra para definir los efectos en el cerebro del Mal de Alzheimer:

Y al cabo de tanto deber hacia los demás, el olvido llegaba. Era una conclusión paradójica, pero avalada por el recuerdo más crudo: mi padre había fallecido en el bosque quemado del Alzheimer, sin memoria ni referencias (172).

Nuevamente en este relato aparecen representadas la historia y sus utopías como una gran traición. El hijo lo refiere de la siguiente forma:

¡Cuántas batallas inútiles!! ¡Cuántos molinos de viento se habría podido evitar de no haber abrazado la dictadura del proletariado como destino científico! ¡Cuántas falsas expectativas! Ah, la sociedad sin clases, la justicia universal, ¡el pensamiento del partido! Es posible que nadie excepto un comunista chileno de los años sesenta comprenda el enorme equívoco que reserva el enunciado

\footnotetext{
35 Roberto Brodsky, Bosque Quemado, Santiago de Chile, Random House Mondadori, 2007. Las citas son de este texto.

${ }^{36}$ Álvaro Bisama, Estrellas muertas, Santiago de Chile, Alfaguara, 2010. Las citas son de este texto.
} 
anterior. Pero ni siquiera así: posiblemente sólo el hijo de un comunista chileno sea capaz de rendir cuenta detallada sobre esta catástrofe (36).

Al narrador de esta historia se le impone la necesidad de hacer el ejercicio de la memoria. Escribir la vida de su padre no estaba en su plan de vida. Pero han estado juntos por años, y de alguna forma, él ha venido siendo alternativamente padre de su padre, padre de su propio hijo, y muy pocas veces, hijo de su padre. La novela es, de cierta forma, un acto de reparación para una memoria traicionada.

En Estrellas muertas de Álvaro Bisama, se narra la historia de Javiera -o lo que se sabe de la historia de Javiera, o lo que se dice que se sabe de la historia de Javiera. Al igual que en Bosque quemado, el punto de partida es una situación de naufragio: una pareja se reúne en un café para realizar los trámites de su divorcio. Este es un naufragio en tono menor: no hay rabias, no hay violencia; hay cariño y una suerte de incomprensión acerca de cómo ocurrieron las cosas, de modo que el proyecto de pareja no funcionó. Sin embargo, el paisaje desde el cual se cuenta, inmediatamente nos pone en situación de abordar el tema de la memoria:

Esas manías eran lo único que nos quedaba en esos días en que los bosques de Laguna Verde se estaban quemando y el viento que venía del sur lanzaba el humo negro sobre el horizonte de los cerros. Con ese cielo oscuro sobre el puerto, yo no dejaba de pensar en que esas cenizas que flotaban en el aire podían ser parecidas a las de los hornos de un campo de concentración, a la borra de la piel humana que deja una bomba atómica. Nosotros estábamos devastados (11).

Pero toda esa sensación de humo y cenizas que envuelve a la pareja, se hace noche oscura y tragedia, cuando ven una noticia en el diario del día: "Ella miró el diario, comenzó a llorar y luego me mostró una foto donde aparecía una mujer escoltada por dos carabineros." (12). Recién entonces, como si estuviéramos abriendo cajas que se esconden unas en otras, se va a redefinir la situación narrativa y nos enfrentaremos a la verdadera historia, la que ha estado oculta, la silenciada:

Yo conozco a esta mina, huevón. Es la Javiera, dijo ella. Es la Javiera, huevón, la que fue compañera mía en la universidad. La Javiera, dijo, la mina que te conté, la que era comunista (15).

El narrador finge conocer la historia, aunque de verdad sólo:

[...] conocía parte de la historia, detalles que ella me había relatado, sin un hilo claro, que eran con suerte las esquirlas y cabos sueltos de las vidas de otros que ella terminó de armar esa mañana; haciendo que la noticia y la foto fueran una escotilla que se cierra y se abre, pero que en ambos casos le dejaba entrever escenas de su propio pasado, un pasado que yo casi no conocía, porque estaba 
enterrado en algún lugar de un puerto donde el cielo aún no se volvía negro ni se respiraba un aire de cenizas, una década y media después (15).

Ya están las cartas echadas: a partir de este momento “él”, el narrador, dará la palabra a "ella", la narradora, que contará la historia de Javiera y el Donoso, pero especialmente de Javiera, quien es la verdadera protagonista de esta novela. ¿Quién es Javiera? Una heroína de la lucha contra la dictadura en los años ochenta, período caracterizado por las grandes protestas. Ella ve la vida desde ese lugar y, puesto que vive en una sociedad que la restringe y la castra, se ubica en el lugar de la trasgresión que, en este caso, será autodestructiva, especialmente al permanecer en una relación amorosa/pasional con un alto contenido de violencia contra la mujer. Cuando se produce la transición a la democracia, ella no tiene la capacidad de adecuar su proyecto a las nuevas condiciones, instalándose en un discurso que nadie -ni siquiera sus antiguos camaradas- quiere escuchar. Dicho en otros términos, la única historia que le proveía identidad le era negada. Para ella, no había memoria suficiente, su memoria había sido traicionada por el olvido.

\section{¿Cuál es la gran traición chilena?}

Partimos este ensayo compartiendo la pregunta que formulara Raúl Zurita: ¿cuál es nuestra gran traición? La novela chilena de las últimas décadas $\mathrm{y}$, especialmente la que se escribe a partir del golpe de estado, le sabe algo a nuestra sociedad y cada tanto se lo recuerda: nos cuesta mirar la realidad y nombrarla tal como es, nos cuesta vernos en toda nuestra complejidad y no vivir de espejismos. En Casa de campo, Donoso acuña una frase que singulariza la actitud con que, a mi parecer, nos acercamos a los hechos de la realidad: cuando ocurre algo desagradable, violento o pervertido, hay que "correr un tupido velo". Y lo que se esconde, la gran traición que devela nuestra literatura, es precisamente estar instalados en una sociedad que nos ofrece un discurso donde nos representamos de cierta forma que está muy lejos de lo que realmente somos. Éramos democráticos y vivimos una dictadura feroz; pensamos que repudiábamos esa dictadura mayoritariamente, y había mucha gente que la respaldaba; reinstalamos la democracia en Chile, pero mantuvimos los enclaves autoritarios; hablamos de un país justo, y tenemos altísimo índices de desigualdad; nos decimos cultos $\mathrm{y}$, sin embargo, no leemos; decimos que necesitamos construir una memoria común y sólo queremos olvidar.

Como titula su última novela el escritor Arturo Fontaine, nuestra gran traición es "la vida doble". Somos una sociedad de máscaras y mentiras, pero jugamos a la verdad. Tarde o temprano, la historia nos pasa la cuenta y se vuelve tragedia. Entonces, volveremos a estas historias y, posiblemente, las miraremos con otros ojos. 


\section{Referencias bibliográficas:}

Alegría, Fernando, Las fronteras del realismo: literatura chilena del siglo XX, Santiago de Chile, Editorial Zigzag, 1962.

Barthes, Roland, El grado cero de la escritura, México, Siglo XXI Editores, 1980.

Bisama, Álvaro, Estrellas muertas, Santiago de Chile, Alfaguara, 2010.

Brodsky, Roberto, Bosque Quemado, Santiago de Chile, Random House Mondadori, 2007.

Cánovas, Rodrigo, Colofón chileno [en Rodrigo Cánovas, Sexualidad y cultura en la novela hispanoamericana, Santiago de Chile, LOM Ediciones, 2003].

Cerda, Carlos, José Donoso: originales y metáforas, Santiago de Chile, Planeta, 1988.

Collyer, Jaime, El infiltrado, Santiago de Chile, Editorial Sudamericana, 1996.

De la Parra, Marco Antonio, Memoria y olvido [en Nelly Richard, ed.: Políticas y estéticas de la memoria, Santiago de Chile, Editorial Cuarto Propio, 2000].

De Ramón, Armando, Historia de Chile. Desde la invasión incaica hasta nuestros días (1500 - 2000), Santiago de Chile, Catalonia, 2003.

Donoso, José, Casa de campo, Barcelona, Seix Barral, 1978. , El jardín de al lado, Barcelona, Seix Barral, 1981.

Eltit, Diamela, Jamás el fuego nunca, Santiago de Chile, Seix Barral, 2011 , Por la patria, Santiago de Chile, Seix Barral, 1986.

Franz, Carlos, Santiago 0, Santiago de Chile, Aguilar chilena de Ediciones, 2008.

Harmer, Tanya y Riquelme Segovia, Alfredo (editores), Chile y la Guerra Fría global, Santiago de Chile, Instituto de Historia PUC Chile - RiL Editores, 2014.

Lillo, Mario, La novela de la dictadura en Chile, “Alpha”, n 29 (2009).

Martínez, Nelly, Entrevista, "Hispanoamérica", nº 21 (1978).

Nelly, Richard, Presentación [en Nelly Richard, ed.: Políticas y estéticas de la memoria, Santiago de Chile, Editorial Cuarto Propio, 2000].

Riquelme Segovia, A., Rojo atardecer. El comunismo chileno entre dictadura y democracia, Santiago de Chile, Centro de Investigaciones Diego Barros Arana, 2009. 
Rivera Soto, José Antonio, La muerte del tiempo utópico en Jamás el fuego nunca de Diamela Eltit, "Acta literaria", n 39 (2009).

Salazar, Manuel, Las letras del horror. Tomo I: La DINA, Santiago de Chile, LOM Ediciones, 2011.

Sarlo, Beatriz, Tiempo pasado, Buenos Aires, Siglo XXI Editores, 2007.

Valdés, Hernán, Tejas verdes, Barcelona, Editorial Laia, 1978.

Valdés, Adriana, Una historia de miedo: cultura, autoritarismo, democratización, [en Adriana Valdés, Composición de lugar. Escritos sobre cultura, Santiago de Chile, Editorial Universitaria, 1996].

Valenzuela, Diego y Ramón Díaz Eterovic, Andar con cuentos, Santiago de Chile, Mosquito Editores, 1992. 1986.

, Contando el cuento, Santiago de Chile, Editorial Sinfronteras,

Zurita, Raúl, Diario La Época, Santiago de Chile, julio 28 de 1987. 
